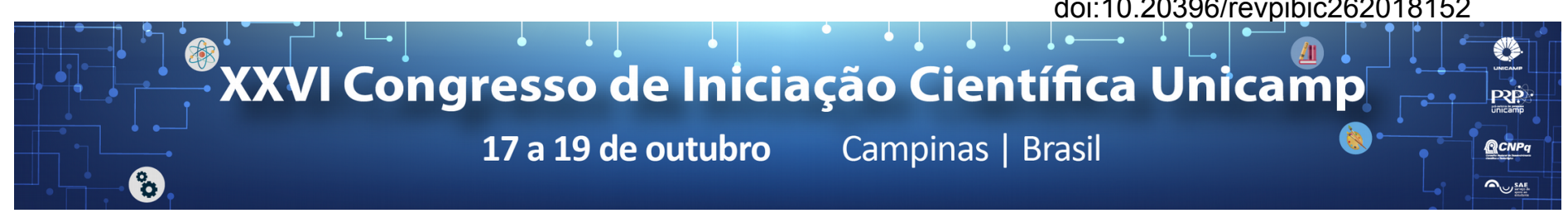

\title{
Aprimoramento de técnicas de hash de similaridade para investigações forenses
}

\author{
André S. Kameyama*, Marco Aurelio A. Henriques.
}

\begin{abstract}
Resumo
Atualmente as investigações forenses têm que lidar com grandes quantidades de dados devido ao avanço da tecnologia, tornando-se impraticável a análise manual de cada caso. Neste trabalho, nós mostramos como melhorar o desempenho e a precisão de uma das ferramentas de pareamento aproximado mais consolidadas na área, o sdhash. Nossos resultados mostram que a ferramenta modificada é capaz de identificar similaridades entre diferentes artefatos com maior facilidade e rapidez.
\end{abstract}

\section{Palavras-chave:}

Função Hash, Resumo Criptográfico, Hash de Similaridade.

\section{Introdução}

A ferramenta de pareamento aproximado sdhash ${ }^{1}$ é utilizada para detecção de similaridade entre objetos digitais de forma eficiente, por meio do uso de representações compactadas, chamadas de hashes de similaridade ou resumo. Esta ferramenta extrai características (features) únicas dos objetos e as codifica em resumos, os quais são mais tarde comparados para se quantificar o quão similares dois objetos são.

Com o intuito de melhorar o processo de identificação de objetos similares, o presente trabalho implementou uma nova versão do sdhash contendo algumas modificações que visam aprimorar tanto sua eficiência, como sua precisão. Foram modificados o processo de seleção de features (a fim de melhorar a precisão do mesmo) e a forma de codificar features (substituição da atual função de hash, SHA-1, por outra mais eficiente, $F N V^{2}$ ). A fim de validar as melhorias propostas, utilizamos uma base de dados gerada localmente para podermos controlar o tamanho e o grau de similaridade de seus objetos.

\section{Resultados e Discussão}

Durante a geração de resumos com o sdhash, são extraídas features de um dado objeto e armazenadas em um vetor temporário. Assim, uma janela de tamanho fixo, iniciada na primeira feature, percorre todo o vetor até alcançar a última, onde em cada iteração, as features pertencentes à janela competem entre si (de acordo com um critério preestabelecido) e a vencedora é selecionada. A janela se move uma posição no vetor e o processo se repete. Porém, as primeiras e as últimas features competem um número menor de vezes em relação às demais, causando uma perda de precisão no processo. A implementação de uma janela circular visa solucionar este problema, uma vez que todas as features irão participar o mesmo número de iterações. Nós constatamos que esta mudança ocasionou um aumentou de aproximadamente $2 \%$ no número total de features selecionadas ao passo que o processo de seleção como um todo se tornou mais justo.

Após a seleção das features, o sdhash calcula o hash de cada uma delas por meio da função de hash SHA-1. Contudo, esta função é computacionalmente custosa e o cálculo da mesma sobre as diversas features que são selecionadas torna o processo lento. Desta forma, substituímos a função de hash por outras mais eficientes, como o MD5 e FNV. Para verificar o impacto dessa troca, foram realizados vários experimentos em diferentes tipos de arquivo. Nos testes foram medidos o tempo de execução e a precisão da ferramenta. $\mathrm{O}$ indicador de precisão utilizado foi o desvio padrão da distribuição das features em um histograma, de forma a simular a colisão entre features dada pela troca da função de hash. Quanto mais próximo o desvio das novas funções está em relação ao desvio de referência (SHA-1), mais próximas estão as distribuições e menor o número de colisões pela troca de função.

Observamos que ambas as funções de hash trouxeram uma diminuição no tempo de execução, sendo que 0 FNV apresentou 0 melhor resultado (aproximadamente 62\%). Em todos os casos o desvio padrão permaneceu o mesmo, portanto podemos adotar essa troca sem perda de qualidade. Em relação à sensibilidade a mudanças nos tipos de arquivos não constatamos variações significativas em nenhum caso.

\section{Conclusão}

Este trabalho buscou aprimorar uma das funções mais utilizadas em investigações forenses para a busca de objetos similares, o sdhash. Mostramos que esta ferramenta possui imprecisões na geração de seus resumos e, através da implementação de uma estrutura de janela circular na etapa de seleção de features, conseguimos solucionar $\mathrm{o}$ problema, tornando $\mathrm{o}$ processo mais justo e aumentando a sensibilidade do mesmo em relação a detecção de mudanças no começo e final de objetos. Também atuamos na melhoria do desempenho do sdhash, trocando a atual função de hash SHA-1 pela FNV, resultando em uma diminuição no tempo de execução sem perda de precisão.

\section{Agradecimentos}

Os autores gostariam de agradecer ao programa PIBIC do CNPq pelo suporte financeiro parcial.

${ }^{1}$ Roussev, V. (2010, January). Data fingerprinting with similarity digests. In IFIP International Conference on Digital Forensics(pp. 207-226). Springer, Berlin, Heidelberg.

2 G. Fowler, L. Noll, P. Vo, Fowler/Noll/Vo (FNV) Hash, ONLINE http://isthe.com/chongo/tech/comp/fnv/ - acessado em 11/07/2018. 